\title{
Identification of QTL underlying physiological and morphological traits of flag leaf in barley
}

\author{
Lipan Liu', Genlou Sun ${ }^{1,2}$, Xifeng Ren ${ }^{1}$, Chengdao $\mathrm{Li}^{3}$ and Dongfa Sun ${ }^{1,4^{*}}$
}

\begin{abstract}
Background: Physiological and morphological traits of flag leaf play important roles in determining crop grain yield and biomass. In order to understand genetic basis controlling physiological and morphological traits of flag leaf, a double haploid $(\mathrm{DH})$ population derived from the cross of Huaai $11 \times$ Huadamai 6 was used to detect quantitative trait locus (QTL) underlying 7 physiological and 3 morphological traits at the pre-filling stage in year 2012 and 2013.

Results: Total of 38 QTLs distributed on chromosome $1 \mathrm{H}, 2 \mathrm{H}, 3 \mathrm{H}, 4 \mathrm{H}, 6 \mathrm{H}$ and $7 \mathrm{H}$ were detected, and explained 6.53\% - 31.29\% phenotypic variation. The QTLs flanked by marker Bmag829 and GBM1218 on chromosome 2H were associated with net photosynthetic rate (Pn), stomatal conductance (Gs), flag leaf area (LA), flag leaf length (FLL), flag leaf width (FLW), relative chlorophyll content (SPD) and leaf nitrogen concentration (LNC).

Conclusion: Two QTL cluster regions associated with physiological and morphological traits, one each on the chromosome $2 \mathrm{H}$ and $7 \mathrm{H}$, were observed. The two markers (Bmag829 and GBM1218) may be useful for marker assisted selection (MAS) in barley breeding.
\end{abstract}

Keywords: Barley, Net photosynthetic rate, Stomatal conductance, Flag leaf area, Flag leaf length, Flag leaf width, Relative chlorophyll content, Leaf nitrogen concentration

\section{Background}

Barley (Hordeum vulgare L.) is the fourth cereal crop in world production [1]. High yield is always one of the important barley breeding aims [2]. However, grain yield was controlled by complex biochemical and physiological processes, and closely related to physiological and morphological traits [3-7]. The top three leaves on a stem, especially the flag leaf, absorb most irradiation light, and were the primary source of carbohydrate production [8]. In barley, importance of flag leaf on increasing grain yield has widely been studied [6,7,9]. However, previous studies have mainly focused on either morphological traits [10-12] or physiological traits of flag leaf [13-18] determining grain yield. Few QTLs associated with these traits have been applied to barley breeding due to complicated measurement procedure, inconsistency and dynamic process of physiological and morphological traits

\footnotetext{
* Correspondence: sundongfa1@mail.hzau.edu.cn

${ }^{1}$ College of Plant Science and Technology, Huazhong Agricultural University, Wuhan 430070, China

${ }^{4}$ Hubei Collaborative Innovation Center for Grain Industry, Wuhan 430070, China

Full list of author information is available at the end of the article
}

in barley developmental stage. Thus, comprehensive understanding the role of physiological and morphological traits of flag leaf on yield will provide a new insight in crop growth and development. Meanwhile, application of molecular marker and genetic map made it possible to map the region controlling quantitative traits $[11,19,20]$.

Increasing photosynthetic capacity of leaf is one of the most important approaches to increase crop biomass [21]. It was estimated that leaf photosynthesis contributing 30\% biomass [2]. Photosynthesis is an essential process to maintain crop growth and development. Photosynthetic capacity during reproductive stage is positively correlated with crop yield [22]. Four main physiological parameters: net photosynthetic rate, stomatal conductance, intercellular $\mathrm{CO}_{2}$ concentration and transpiration rate, have been used to evaluate photosynthetic capacity. Teng et al. [2] reported that net photosynthetic rate in rice was controlled by multiple genes. In barley, QTL underlying net photosynthetic rate has been analyzed in two DH populations [18]. According to Jiang et al. [23], stomatal conductance significantly affected net photosynthetic rate, and is a key parameter to assess limitation of photosynthesis in barley. Rybiński et al. [24] found significant linear relationship 
between transpiration rate and net photosynthetic rate in different irradiated times under laser light. However, the QTLs underlying stomatal conductance, intercellular $\mathrm{CO}_{2}$ concentration and transpiration rate have not been reported in barley.

Chlorophyll absorbs light energy and converts it into chemical energy. Maintaining higher level of chlorophyll content in leaf is one of the strategies for increasing photosynthesis and crop production [14]. The structure and function of chloroplasts determine photosynthetic activity [25]. Von Kroff et al. [26] reported a positive correlation between relative chlorophyll fluorescence in leaf and grain yield. The chlorophyll content was suggested as a reliable indicator for evaluating metabolic balance between photosynthesis and yield performance [27]. Recently, chlorophyll content in barley leaf has widely been studied [11,14,26,28].

Nitrogen uptake and metabolism of flag leaf at the prefilling stage provide main energy source to grain yield [15]. The photosynthetically active leaf cells of chloroplasts contain most nitrogen [29]. The most of assimilated nitrogen mainly come from photosynthesis. Leaf $\mathrm{CO}_{2}$ assimilation rate and nitrogen content per unit area was highly correlated [30]. Depending on physiological status, nitrogen can be stored and assimilated in both leaves and roots [31]. In fully developed leaves, about 75\% nitrogen is allocated to chloroplasts, and mostly used for synthesizing components of photosynthetic apparatus [32]. A positive correlation was found between photosynthetic capacity of leaves and their nitrogen content [33]. In past few years, some studies have reported that nitrogen content in leaves was quantitative trait and controlled by multiple genes in barley. Stable QTLs were detected, but phenotypic contribution from each QTL was small [12,15,29].

Plant water status plays an important role in plant growth, development, and keeping yield stability [34]. The physiological and morphological traits such as photosynthesis, transpiration of flag leaves and grain yield are closely correlated with plant water status $[35,36]$. In water deficit environment, crop must increases water use efficiency to resist drought, and sustains normal growth [37]. Relative water content (RWC) was widely used to measure water status in barley [38]. RWC is an important determinant of leaf metabolic activity, and reflects water balance in tissues [39]. Maintenance of certain level of RWC can increase yield and its stability in cereals [38]. As RWC is related to plant water-status, it can be used to evaluate water level in plant at a specific growth stage. It has been reported that RWC has a positive relationship with yield in cereals [36]. QTLs associated with RWC were detected on chromosome $6 \mathrm{H}$ in different water conditions and developmental stages $[16,40,41]$.

In present study, a $\mathrm{DH}$ population derived from the cross of Huaai $11 \times$ Huadamai 6 was used to identify
QTLs underlying physiological and morphological traits of flag leaf at the pre-filling stage. The identified QTLs can be used for molecular assisted selection (MAS) in barley breeding.

\section{Results}

Phenotype analysis of the double population and parents The statistics of 7 physiological and 3 morphological traits of flag leaf at the pre-filling stage were shown in Table 1. The values of Pn, Gs, Ci, Tr, RWC, SPD and LNC in Huaai 11 were higher than those in Huadamai 6. The values of LA, FLL and FLW were higher in Huadamai 6 than those in Huaai 11. The $t$-test showed that two parents were significant difference on all traits $(p<0.05)$. All traits displayed a normal distribution with the skewness and kurtosis among -1 and 1 (Table 1). Analysis of variance showed that genotype effects were significant $(P<0.01)$ for all traits studied. Effects between years were not significant ( $\mathrm{P}>0.05$ ) except Pn, Gs and Tr traits. Genotype $\times$ year interactions were significant $(\mathrm{P}<0.05)$ for all traits except LA, FLL and FLW (Table 2). In addition, all 7 physiological and 3 morphological traits at the pre-filling stage showed highly phenotypic variation in the $\mathrm{DH}$ population. The variable coefficients ranged from $5.22 \%$ to $30.91 \%$ in 2012 , and $11.50 \%$ to $28.50 \%$ in 2013 . Transgressive segregation in both directions was observed for all traits (Table 1). Heritability (Table 1) ranged from $44.13 \%$ to $80.67 \%$ and $52.66 \%$ to $85.57 \%$ in 2012 and 2013 , respectively.

\section{Correlation analysis}

Correlations among Pn, Gs, Ci, and Tr were significant positive $(\mathrm{P}<0.01$, Table 3$)$. Three morphological traits, LA, FLL and FLW, were also significantly positive correlated with each other $(\mathrm{P}<0.01$, Table 3$)$. Significant positive correlation between Pn and SPD was detected with correlation coefficient of 0.335 in 2012 and 0.265 in 2013 $(\mathrm{P}<0.01)$. LNC was significantly correlated with SPD $(\mathrm{r}=$ 0.283 in 2012 and 0.381 in 2013, $\mathrm{P}<0.01$ ). A negative correlation between Pn and LA was observed with $\mathrm{r}=-0.515$ (year 2012) and -0.225 (year 2013) $(\mathrm{P}<0.05)$. RWC was not significantly $(\mathrm{P}>0.05)$ correlated with other traits except LA in 2013.

\section{QTL analysis}

A total of 38 QTLs for 7 physiological and 3 morphological traits were detected and mapped (Figure 1; Table 4). 18 and 15 QTLs were detected in 2012 and 2013, respectively. Five QTLs based on mean value of each trait were detected for LA, FLL and FLW. The detected QTLs accounted for $7.14 \%$ - $24.58 \%$ and $6.53 \%$ - $25.36 \%$ phenotypic variation in 2012 and 2013, respectively. The QTLs based on mean values of LA, FLL and FLW explained $14.23 \%-31.29 \%$ phenotypic variation. 
Table 1 The statistics of the 122 lines from DH population and parents for the 7 physiological and 3 morphological traits based on data from each year (2012 and 2013)

\begin{tabular}{|c|c|c|c|c|c|c|c|c|c|c|c|c|c|c|}
\hline \multirow[t]{2}{*}{ Trait } & \multirow[t]{2}{*}{ Year } & \multicolumn{2}{|l|}{ Huadamai6 } & \multicolumn{2}{|l|}{ Huaai11 } & \multirow[t]{2}{*}{ ST } & \multicolumn{8}{|c|}{ DH lines } \\
\hline & & Mean & SD & Mean & SD & & $\operatorname{Max}$ & Min & Mean & SD & Skewness & Kurtosis & CV (\%) & H (\%) \\
\hline \multirow[t]{2}{*}{$\overline{P n}$} & 2012 & $26.00 \pm 1.17$ & 2.87 & $29.38 \pm 0.55$ & 1.35 & $0.041^{*}$ & 32.56 & 19.72 & $25.15 \pm 0.24$ & 2.62 & 0.23 & -0.13 & 10.41 & 44.13 \\
\hline & 2013 & $22.77 \pm 0.10$ & 1.17 & $25.03 \pm 2.71$ & 4.69 & $0.031^{*}$ & 27.77 & 14.44 & $20.31 \pm 0.21$ & 2.33 & 0.26 & 0.39 & 11.50 & 56.85 \\
\hline \multirow[t]{2}{*}{ Gs } & 2012 & $0.43 \pm 0.03$ & 0.06 & $1.03 \pm 0.03$ & 0.07 & $0.000^{* *}$ & 1.02 & 0.21 & $0.56 \pm 0.02$ & 0.17 & 0.19 & -0.53 & 30.91 & 53.34 \\
\hline & 2013 & $0.46 \pm 0.01$ & 0.01 & $0.83 \pm 0.07$ & 0.12 & $0.036^{*}$ & 0.93 & 0.20 & $0.41 \pm 0.01$ & 0.14 & 1.00 & 1.00 & 33.05 & 58.56 \\
\hline \multirow[t]{2}{*}{$\mathrm{Ci}$} & 2012 & $255.83 \pm 2.70$ & 6.62 & $308.67 \pm 1.09$ & 2.66 & $0.000^{* *}$ & 316.51 & 197.1 & $266.84 \pm 2.38$ & 26.24 & -0.78 & 0.19 & 9.84 & 60.76 \\
\hline & 2013 & $261.32 \pm 1.87$ & 3.23 & $294.89 \pm 0.42$ & 0.73 & $0.005^{* *}$ & 315.71 & 216.3 & $268.01 \pm 1.77$ & 19.55 & 0.14 & -0.31 & 7.29 & 65.23 \\
\hline \multirow[t]{2}{*}{$\operatorname{Tr}$} & 2012 & $6.45 \pm 0.30$ & 0.73 & $9.28 \pm 0.16$ & 0.39 & $0.001^{* *}$ & 12.83 & 4.87 & $8.21 \pm 0.14$ & 1.59 & 0.04 & -0.38 & 19.32 & 47.65 \\
\hline & 2013 & $7.47 \pm 0.04$ & 0.08 & $9.86 \pm 1.00$ & 1.73 & $0.028^{*}$ & 10.41 & 3.78 & $6.27 \pm 0.13$ & 1.44 & 0.38 & -0.34 & 22.95 & 52.66 \\
\hline \multirow[t]{2}{*}{ LA } & 2012 & $27.18 \pm 0.88$ & 2.80 & $12.02 \pm 0.83$ & 2.63 & $0.000^{* *}$ & 30.42 & 9.66 & $17.89 \pm 0.37$ & 4.08 & 0.69 & 0.19 & 22.82 & 78.98 \\
\hline & 2013 & $26.66 \pm 1.80$ & 4.76 & $18.05 \pm 1.43$ & 3.80 & $0.002^{* *}$ & 37.79 & 10.37 & $21.52 \pm 0.47$ & 5.18 & 0.63 & 0.55 & 24.10 & 83.56 \\
\hline \multirow[t]{2}{*}{ FLL } & 2012 & $26.62 \pm 1.08$ & 3.41 & $14.36 \pm 0.81$ & 2.57 & $0.000^{* *}$ & 28.02 & 13.04 & $17.94 \pm 0.24$ & 2.66 & 0.28 & -0.43 & 14.84 & 80.67 \\
\hline & 2013 & $22.31 \pm 0.88$ & 2.34 & $15.84 \pm 0.88$ & 2.33 & $0.000^{* *}$ & 27.39 & 12.86 & $19.09 \pm 0.26$ & 2.88 & 0.44 & 0.21 & 15.08 & 85.57 \\
\hline \multirow[t]{2}{*}{ FLW } & 2012 & $2.03 \pm 0.13$ & 0.40 & $1.48 \pm 0.05$ & 0.16 & $0.003^{* *}$ & 2.20 & 1.22 & $1.67 \pm 0.02$ & 0.19 & 0.56 & 0.27 & 11.60 & 69.34 \\
\hline & 2013 & $1.97 \pm 0.04$ & 0.11 & $1.56 \pm 0.06$ & 0.15 & $0.012^{*}$ & 2.18 & 1.21 & $1.74 \pm 0.02$ & 0.18 & 0.10 & 0.13 & 10.53 & 76.56 \\
\hline \multirow[t]{2}{*}{ RWC } & 2012 & $80.96 \pm 0.52$ & 1.65 & $87.13 \pm$ & 3.01 & $0.015^{*}$ & 92.26 & 73.53 & $82.68 \pm 0.39$ & 4.31 & 0.11 & -0.59 & 5.22 & 50.56 \\
\hline & 2013 & $82.62 \pm 3.90$ & 8.71 & $86.05 \pm 3.59$ & 8.02 & $0.050^{*}$ & 94.23 & 72.08 & $83.38 \pm 0.41$ & 4.49 & -0.24 & -0.16 & 5.38 & 57.67 \\
\hline \multirow[t]{2}{*}{ SPD } & 2012 & $52.50 \pm 1.23$ & 2.13 & $65.87 \pm 0.79$ & 1.37 & $0.007^{* *}$ & 71.93 & 51.17 & $62.33 \pm 0.38$ & 4.17 & -0.27 & -0.15 & 6.69 & 49.56 \\
\hline & 2013 & $51.63 \pm 3.17$ & 5.49 & $62.83 \pm 1.79$ & 3.10 & $0.035^{*}$ & 66.33 & 48.33 & $59.07 \pm 0.33$ & 3.67 & -0.48 & 0.41 & 6.22 & 57.89 \\
\hline \multirow[t]{2}{*}{ LNC } & 2012 & $2.90 \pm 0.07$ & 0.17 & $4.70 \pm 0.25$ & 0.60 & $0.002^{* *}$ & 7.88 & 1.41 & $4.79 \pm 0.12$ & 1.38 & -0.39 & -0.53 & 28.76 & 70.45 \\
\hline & 2013 & $3.84 \pm 0.18$ & 0.43 & $5.01 \pm 0.21$ & 0.51 & $0.000^{* *}$ & 7.96 & 1.68 & $4.89 \pm 0.13$ & 1.39 & -0.38 & -0.38 & 28.50 & 62.45 \\
\hline
\end{tabular}

${ }^{* *}$ : Significant at 0.05, 0.01 level, respectively.

ST: Significant; CV: Coefficient of variation; H: Heritability.

\section{Net photosynthetic rate}

Three QTL underlying Pn trait were detected. Two QTLs, qPn2-10 and qPn4-17, were detected on chromosome $2 \mathrm{H}$ and $4 \mathrm{H}$ in 2012. They accounted for $8.66 \%$ and $12.63 \%$ total phenotypic variation, respectively. The QTL, qPn7-8 on chromosome 7H was detected in 2013, and accounted for $13.56 \%$ total phenotypic variation. Both qPn2-10 and qPn7-8 QTLs have alleles from Huaai 11 to increase net photosynthetic rate, the QTL qPn4-17 has allele from Huadamai 6 to increase net photosynthetic rate (Figure 1; Table 4).

\section{Stomatal conductance}

Four QTLs associated with Gs trait were detected. Of them, three QTLs, qGs2-10, qGs3-13 and qGs7-6, were detected in 2012 and mapped on chromosome $2 \mathrm{H}, 3 \mathrm{H}$ and $7 \mathrm{H}$, and accounted for $7.78 \%, 12.58 \%$ and $13.92 \%$ total phenotypic variation, respectively. In 2013, one QTL qGs2-13 was detected on chromosome $2 \mathrm{H}$, and accounted for $7.47 \%$ total phenotypic variation. All these QTLs have alleles from Huaai 11 to increase stomatal conductance, their values ranged from 0.04 to 0.07 (Figure 1; Table 4).

\section{Intercellular $\mathrm{CO}_{2}$ concentration}

Three QTLs for Ci trait were detected. Of them, two QTLs, qCi2-16 and qCi7-3, were mapped on chromosome $2 \mathrm{H}$ and $7 \mathrm{H}$ in 2012, and accounted for $13.75 \%$ and $13.98 \%$ total phenotypic variation, respectively. One QTL qCi2-14 was identified in 2013, and accounted for $10.69 \%$ total phenotypic variation. These QTLs have

Table 2 Variance analysis of 7 physiological and 3 morphological traits of 122 barley DH lines, sum of squares was shown

\begin{tabular}{lllllllllll}
\hline Source & Pn & Gs & Ci & Tr & LA & FLL & FLW & RWC & SPD & LNC \\
\hline Genotype & $7055.203^{* *}$ & $16.755^{* *}$ & $495793.084^{* *}$ & $1796.972^{* *}$ & $28542.641^{* *}$ & $7344.367^{* *}$ & $31.652^{* *}$ & $13868.241^{* *}$ & $14379.196^{* *}$ & $757.609^{* *}$ \\
Year & $3651.228^{* *}$ & $6.290^{*}$ & 289.943 & $703.441^{* *}$ & 317.510 & 161.339 & 1.813 & 73.509 & 603.316 & 3.493 \\
Genotype $\times$ Year & $2593.407^{* *}$ & $6.803^{*}$ & $52994.676^{*}$ & $646.039^{* *}$ & 1371.505 & 671.623 & 3.679 & $2100.091^{*}$ & $2570.247^{*}$ & $96.884^{*}$ \\
\hline
\end{tabular}

\footnotetext{
${ }^{*},{ }^{* *}$ : Significant at 0.05 and 0.01 level, respectively.
} 
Table 3 Correlation analysis among 7 physiological and 3 morphological traits based on data from each year

\begin{tabular}{|c|c|c|c|c|c|c|c|c|c|c|}
\hline Trait & Pn & Gs & $\mathrm{Ci}$ & $\mathrm{Tr}$ & LA & FLL & FLW & RWC & SPD & LNC \\
\hline$\overline{P n}$ & & $0.655^{* *}$ & $0.474^{* *}$ & $0.675^{* *}$ & $-0.515^{* *}$ & $-0.416^{* *}$ & $-0.562^{* *}$ & 0.088 & $0.335^{* *}$ & 0.002 \\
\hline Gs & $0.657^{* *}$ & & $0.892^{* *}$ & $0.918^{* *}$ & $-0.454^{* *}$ & $-0.407^{* *}$ & $-0.450^{* *}$ & 0.067 & $0.527^{* *}$ & 0.160 \\
\hline $\mathrm{Ci}$ & $0.373^{* *}$ & $0.891^{* *}$ & & $0.767^{* *}$ & $-0.482^{* *}$ & $-0.477^{* *}$ & $-0.422^{* *}$ & -0.044 & $0.499^{* *}$ & 0.171 \\
\hline $\mathrm{Tr}$ & $0.701^{* *}$ & $0.930^{* *}$ & $0.830^{* *}$ & & $-0.498^{* *}$ & $-0.422^{* *}$ & $-0.517^{* *}$ & 0.055 & $0.612^{* *}$ & 0.120 \\
\hline LA & $-0.225^{*}$ & $-0.376^{* *}$ & $-0.417^{* *}$ & $-0.497^{* *}$ & & $0.864^{* *}$ & $0.861^{* *}$ & 0.171 & $-0.472^{* *}$ & -0.082 \\
\hline FLL & $-0.188^{*}$ & $-0.390^{* *}$ & $-0.428^{* *}$ & $-0.504^{* *}$ & $0.942^{* *}$ & & $0.585^{* *}$ & 0.055 & $-0.392^{* *}$ & -0.025 \\
\hline FLW & $-0.213^{*}$ & $-0.336^{* *}$ & $-0.390^{* *}$ & $-0.440^{* *}$ & $0.863^{* *}$ & $0.684^{* *}$ & & 0.165 & $-0.420^{* *}$ & -0.017 \\
\hline RWC & 0.017 & 0.021 & 0.006 & -0.097 & $0.183^{*}$ & 0.127 & 0.144 & & -0.050 & 0.088 \\
\hline SPD & $0.265^{* *}$ & $0.193^{*}$ & $0.274^{* *}$ & $0.253^{* *}$ & $-0.392^{* *}$ & $-0.377^{* *}$ & $-0.355^{* *}$ & -0.003 & & $0.283^{* *}$ \\
\hline LNC & 0.011 & 0.110 & $0.201^{*}$ & 0.144 & $-0.216^{*}$ & $-0.231^{*}$ & -0.144 & -0.011 & $0.381^{* *}$ & \\
\hline
\end{tabular}

${ }^{*},{ }^{* *}$ : Significant at $0.05,0.01$ level, respectively.

Values above the diagonal are correlation coefficients in 2012; values below the diagonal are correlation coefficients in 2013.

alleles from Huaai 11 to increase intercellular $\mathrm{CO}_{2}$ concentration (Figure 1; Table 4).

\section{Transpiration rate}

Two QTLs underlying Tr trait were identified in 2012. The QTL qTr3-13 and qTr7-6 accounted for $14.00 \%$ and $14.02 \%$ total phenotypic variation, respectively. The additive effects of the two QTLs were 0.69 and 0.71 , respectively, indicating that the alleles from Huaai 11 increased transpiration rate (Figure 1; Table 4).

\section{Flag leaf area}

Four QTLs underlying LA trait were detected on chromosome $2 \mathrm{H}$ and $3 \mathrm{H}$. The QTL, qLA2-12 close to the marker GBM1218, was detected in both years and mean value, and accounted for $18.80 \%$ (year 2012), $12.48 \%$ (year 2013) and $29.83 \%$ (mean value from two years) phenotypic variation. The alleles from Huadamai 6 increased flag leaf area. Another QTL qLA3-9 detected in 2013 accounted for $8.72 \%$ phenotypic variation. The allele of QTL qLA3-9 from Huaai 11 increased flag leaf area (Figure 1; Table 4).

\section{Flag leaf length}

Seven QTLs associated with FLL trait were detected. The QTL, qFLL2-12 close to the marker GBM1218 on chromosome $2 \mathrm{H}$, was detected in both years and mean value, and accounted for $24.58 \%$ (year 2012), 25.36\% (year 2013) and $31.29 \%$ (mean value from two years) phenotypic variation. The alleles of the QTL, which increased flag leaf length, came from Huadamai 6. Other four QTLs, qFLL7-10, qFLL3-11, qFLL7-6 and qFLL7-8, accounted for $13.04 \%, 9.76 \%, 7.07 \%$ and $16.66 \%$ total phenotypic variation, respectively. The positive alleles of QTL qFLL7-10, qFLL3-11, qFLL7-6 and qFLL7-8 from Huadamai 6 contributed to the increase in flag leaf length by 1.06, 0.98, 0.79 and 1.14, respectively (Figure 1; Table 4).

\section{Flag leaf width}

For FLW trait, five putative QTLs were identified. The QTL, qFLW2-12 close to the marker GBM1218 on chromosome $2 \mathrm{H}$, was detected in both years and mean value, and accounted for 13.63\% (year 2012), 20.93\% (year 2013) and 14.23\% (mean value from two years) total phenotypic variation. The positive alleles of QTL qFLW2-12 from Huadamai 6 increased flag leaf width. Another QTL qFLW4-18 detected in 2013 and mean value was located on chromosome $4 \mathrm{H}$, and accounted for $7.11 \%$ and $22.06 \%$ total phenotypic variation, respectively. The alleles of qFLW4-18 from Huaai 11 contributed to the increase in flag leaf width (Figure 1; Table 4).

\section{Relative water content}

Three QTLs underlying RWC were found. The QTL qRWC6-6 nearby the marker GMS6 on chromosome $6 \mathrm{H}$ was detected in both years, and accounted for 21.43\% (year 2012) and $11.76 \%$ (year 2013) phenotypic variation. Their alleles from Huadamai 6 increased relative water content. Another QTL, qRWC7-9 was detected in year 2012 and mapped on chromosome 7H, which accounted for $15.31 \%$ phenotypic variation. The allele from Huaai 11 increased relative water content (Figure 1; Table 4).

\section{Relative chlorophyll content}

Four QTLs underlying SPD trait were found. The QTL qSPD2-10 was detected in both years and close to the marker Bmag829 on chromosome $2 \mathrm{H}$, and accounted for $17.28 \%$ (year 2012) and $15.44 \%$ (year 2013) total phenotypic variation. Two QTLs, qSPD7-7 and qSPD79, were mapped on chromosome $7 \mathrm{H}$ and close to the marker Bmac167 (year 2012) and Bmag746 (year 2013). They accounted for $10.78 \%$ and $10.64 \%$ total phenotypic variation in year 2012 and 2013, respectively. All these QTLs have alleles from Huaai 11 contributed to the increase in relative chlorophyll content (Figure 1; Table 4). 


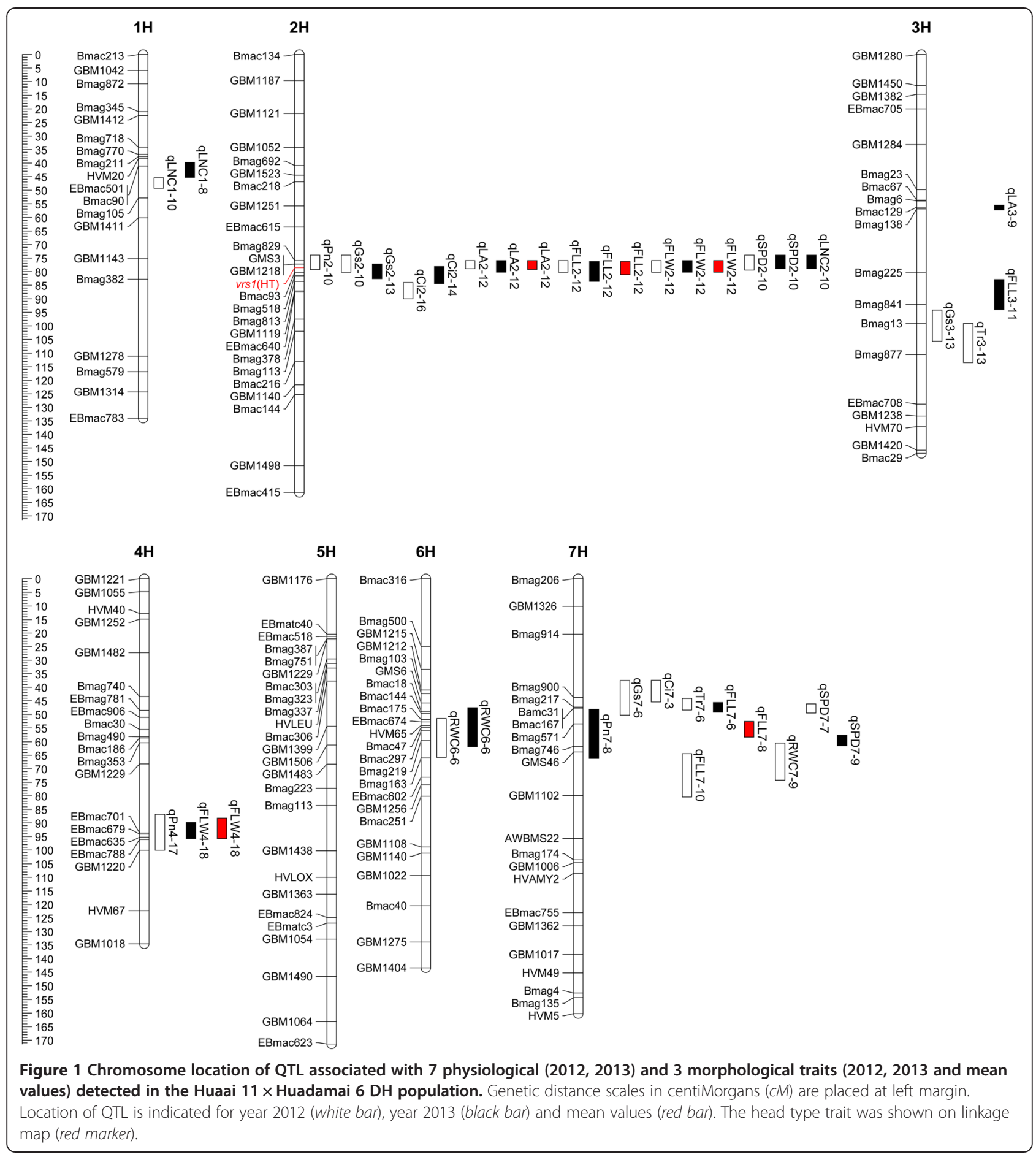

\section{Total nitrogen content}

Three QTLs associated with LNC trait were detected. Of them, one QTL, qLNC1-10 on chromosome $1 \mathrm{H}$, was detected in 2012 and accounted for 7.14\% phenotypic variation. Two QTLs qLNC1-8 and qLNC2-10 were mapped on chromosome $1 \mathrm{H}$ and $2 \mathrm{H}$ in 2013, and accounted for $8.46 \%$ and $6.53 \%$ phenotypic variation, respectively. All these QTLs have alleles from Huaai 11 contributed to the increase in total nitrogen content (Figure 1; Table 4).

\section{Discussion}

QTL analysis is a useful approach to discover and identify favorable alleles in barley [42]. Ren et al. [43] have studied the correlation and QTL of agronomic and quality traits associated with grain yield in a barley $\mathrm{DH}$ 
Table 4 QTL detected for 7 physiological and 3 morphological traits based on data form year 2012, 2013 and mean value form two years

\begin{tabular}{|c|c|c|c|c|c|c|c|c|c|}
\hline Trait & Year & QTL & Chromosome & Nearest marker & Position (cM) & Interval (cM) & LOD & Explained variance (\%) & Additive effect \\
\hline \multirow[t]{3}{*}{$\overline{P n}$} & 2012 & qPn2-10 & 2 & Bmag829 & 75.9 & $73.9-79.2$ & 3.43 & 8.66 & -0.94 \\
\hline & 2012 & qPn4-17 & 4 & EBmac788 & 96.1 & $86.8-100.1$ & 4.64 & 12.63 & 1.09 \\
\hline & 2013 & qPn7-8 & 7 & Bmag571 & 53.5 & $48.1-66.2$ & 4.86 & 13.56 & -1.19 \\
\hline \multirow[t]{4}{*}{ Gs } & 2012 & qGs2-10 & 2 & Bmag829 & 75.9 & $73.9-80.2$ & 3.49 & 7.78 & -0.05 \\
\hline & 2012 & qGs3-13 & 3 & Bmag13 & 97.6 & $94.2-105.7$ & 5.44 & 12.58 & -0.07 \\
\hline & 2012 & qGs7-6 & 7 & Bmac31 & 47.1 & $37.5-50.3$ & 5.95 & 13.92 & -0.07 \\
\hline & 2013 & qGs2-13 & 2 & Bmac93 & 80.2 & $77.2-82.6$ & 3.04 & 7.47 & -0.04 \\
\hline \multirow[t]{3}{*}{$\mathrm{Ci}$} & 2012 & qCi2-16 & 2 & GBM1119 & 87.1 & $84.0-90.0$ & 4.93 & 13.75 & -9.62 \\
\hline & 2012 & qCi7-3 & 7 & Bmag914 & 42.4 & $37.4-45.4$ & 5.01 & 13.98 & -9.78 \\
\hline & 2013 & qCi2-14 & 2 & Bmag518 & 81.5 & $78.1-84.4$ & 3.75 & 10.69 & -7.78 \\
\hline \multirow[t]{2}{*}{$\operatorname{Tr}$} & 2012 & qTr3-13 & 3 & Bmag13 & 103.6 & $99.1-113.5$ & 4.51 & 14.00 & -0.69 \\
\hline & 2012 & qTr7-6 & 7 & Bmac31 & 47.1 & $44.1-48.4$ & 5.58 & 14.02 & -0.71 \\
\hline \multirow[t]{4}{*}{ LA } & 2012 & qLA2-12 & 2 & GBM1218 & 77.2 & $75.9-78.9$ & 7.09 & 18.80 & 2.17 \\
\hline & 2013 & qLA2-12 & 2 & GBM1218 & 77.2 & $75.9-80.2$ & 5.22 & 12.48 & 2.00 \\
\hline & 2013 & qLA3-9 & 3 & Bmac129 & 56.3 & $55.5-57.3$ & 3.77 & 8.72 & -1.81 \\
\hline & Mean & qLA2-12 & 2 & GBM1218 & 77.2 & $75.9-79.2$ & 14.17 & 29.83 & 2.53 \\
\hline \multirow[t]{7}{*}{ FLL } & 2012 & qFLL2-12 & 2 & GBM1218 & 77.2 & $75.9-80.2$ & 9.98 & 24.58 & 1.52 \\
\hline & 2012 & qFLL7-10 & 7 & GMS46 & 72.4 & $64.4-80.4$ & 4.59 & 13.04 & 1.06 \\
\hline & 2013 & qFLL2-12 & 2 & GBM1218 & 79.2 & $76.2-83.6$ & 10.16 & 25.36 & 1.53 \\
\hline & 2013 & qFLL3-11 & 3 & Bmag225 & 83.4 & $82.9-94.0$ & 3.53 & 9.76 & 0.98 \\
\hline & 2013 & qFLL7-6 & 7 & Bmac31 & 47.1 & $45.6-49.2$ & 3.22 & 7.07 & 0.79 \\
\hline & Mean & qFLL2-12 & 2 & GBM1218 & 79.2 & $76.2-81.1$ & 14.98 & 31.29 & 1.55 \\
\hline & Mean & qFLL7-8 & 7 & Bmag571 & 55.5 & $52.6-58.3$ & 8.81 & 16.66 & 1.14 \\
\hline \multirow[t]{5}{*}{ FLW } & 2012 & qFLW2-12 & 2 & GBM1218 & 77.2 & $75.9-80.2$ & 5.57 & 13.63 & 0.08 \\
\hline & 2013 & qFLW2-12 & 2 & GBM1218 & 77.2 & $75.9-80.2$ & 7.86 & 20.93 & 0.09 \\
\hline & 2013 & qFLW4-18 & 4 & GBM1220 & 93.8 & $89.8-95.8$ & 3.19 & 7.11 & -0.05 \\
\hline & Mean & qFLW2-12 & 2 & GBM1218 & 77.2 & $75.9-80.2$ & 7.31 & 14.23 & 0.08 \\
\hline & Mean & qFLW4-18 & 4 & GBM1220 & 93.8 & $88.2-95.8$ & 8.90 & 22.06 & -0.09 \\
\hline \multirow[t]{3}{*}{ RWC } & 2012 & qRWC6-6 & 6 & GMS6 & 57.8 & $51.5-65.8$ & 6.35 & 21.43 & 2.03 \\
\hline & 2012 & qRWC7-9 & 7 & Bmag746 & 62.3 & $60.5-74.2$ & 5.77 & 15.31 & -1.74 \\
\hline & 2013 & qRWC6-6 & 6 & GMS6 & 53.8 & $47.5-61.8$ & 3.15 & 11.76 & 1.72 \\
\hline \multirow[t]{4}{*}{ SPD } & 2012 & qSPD2-10 & 2 & Bmag829 & 75.9 & $73.9-79.4$ & 6.97 & 17.28 & -2.08 \\
\hline & 2012 & qSPD7-7 & 7 & Bmac167 & 47.5 & $46.1-49.5$ & 4.57 & 10.78 & -1.57 \\
\hline & 2013 & qSPD2-10 & 2 & Bmag829 & 75.9 & $73.9-78.9$ & 6.27 & 15.44 & -1.56 \\
\hline & 2013 & qSPD7-9 & 7 & Bmag746 & 58.9 & $57.6-61.5$ & 4.48 & 10.64 & -1.34 \\
\hline \multirow[t]{3}{*}{ LNC } & 2012 & qLNC1-10 & 1 & EBmac501 & 48.1 & $45.4-49.3$ & 3.27 & 7.14 & -0.24 \\
\hline & 2013 & qLNC1-8 & 1 & Bmag211 & 41.1 & $39.7-45.3$ & 3.37 & 8.46 & -0.29 \\
\hline & 2013 & qLNC2-10 & 2 & Bmag829 & 75.9 & $73.9-78.9$ & 3.12 & 6.53 & -0.17 \\
\hline
\end{tabular}

population. However, QTL associated with physiological and morphological traits of flag leaf at the pre-filling stage have not been systematically analyzed.

Leaf net photosynthetic rate was easily affected by environment factors. It was reported the net photosynthetic rate was different in different environments including illumination intensity, temperature, content of $\mathrm{CO}_{2}$ and moisture in the air [44]. In our experiment, we selected 9:00-11:00 am and 2:00-4:00 pm to measure photosynthesis based on the daily change rule of photosynthesis 
and our operational experience that photosynthesis was stable at these two time periods. In plant developmental stage, the four traits Pn, Gs, Ci and Tr index reflect plant photosynthetic capacity. The all four traits were closely related to grain yield. QTLs underlying Pn, Gs and Tr have been analyzed in rice [2]. Wójcik-Jagła et al. [18] analyzed QTL underlying net photosynthetic rate in barley, and found one QTL nearby the marker bPb-8013 on chromosome $4 \mathrm{H}$ in the Suweren $\times$ MOB12055 population, one QTL on chromosome $5 \mathrm{H}$ in the STH754 $\times$ STH836 population. In our study, we detected one QTL nearby the marker EBmac788 on chromosome $4 \mathrm{H}$. The consensus map of Wenzl et al. [20] showed that the marker bPb8013 is far from EBmac788, indicating that the qPn4-17 was a new QTL identified here. In rice, QTL analysis of several physiological traits related to photosynthesis had been performed [2]. In our study, 9 QTLs controlling Gs, $\mathrm{Ci}$ and $\mathrm{Tr}$ traits in barley flag leaf were detected. The identified QTLs may be useful for MAS in barley breeding.

To sustain crop growth and development, crop must produce abundant nutrition. The amount of nutrition produced mainly depends on flag leaf associated with Pn, SPD, LNC and LA, which were closely related to grain yield and biomass [3,7,9]. Four QTLs associated with relative chlorophyll content were detected. QTL qSPD2-10 was detected at $75.9 \mathrm{cM}$ in 2012 and 2013, indicating this QTL was stable and less affected by environments. In barley, This et al. [17] detected 12 QTLs underlying chlorophyll content on chromosome $2 \mathrm{H}, 4 \mathrm{H}$, $5 \mathrm{H}, 6 \mathrm{H}$ and $7 \mathrm{H}$. Xue et al. [11] detected two QTLs underlying chlorophyll content on chromosome $2 \mathrm{H}$. One QTL related to SPD trait has mapped on chromosome $2 \mathrm{H}$ [26]. The high density consensus map [42] indicated the qSPD2-10 was close to the QTL (qFC2.2) [11], between marker Bmag0518 and Bmac0093. The QTL qSPD7-7 and qSPD7-9 were close to the centromere of chromosome $7 \mathrm{H}$, and different from the QTL on chromosome $7 \mathrm{H}$ reported previously $[17,28]$. Five QTLs controlling nitrogen content of flag leaf were detected on chromosome $2 \mathrm{H}, 3 \mathrm{H}, 5 \mathrm{H}$ and $7 \mathrm{H}$ [12]. Mickelson et al. [15] detected 19 QTLs on chromosome 3H, $4 \mathrm{H}, 5 \mathrm{H}, 6 \mathrm{H}$ and $7 \mathrm{H}$ associated with nitrogen concentration in flag leaf. Three QTLs underlying LNC trait were detected on chromosome $1 \mathrm{H}$ and $2 \mathrm{H}$ in our study, indicating that the two QTLs on chromosome $1 \mathrm{H}$ may be new QTL underlying nitrogen concentration in flag leaf. The QTL qLNC2-10 on centromere region of chromosome $2 \mathrm{H}$ is different from the QTL on chromosome $2 \mathrm{H}$ reported previously [12]. Four QTLs associated with flag leaf area were identified. The QTL qLA2-12 on chromosome $2 \mathrm{H}$ located at $77.2 \mathrm{cM}$ was detected in both years and mean value. Previous studies reported QTL underlying leaf area on chromosome $1 \mathrm{H}, 2 \mathrm{H}, 3 \mathrm{H}, 4 \mathrm{H}, 5 \mathrm{H}$ and $7 \mathrm{H}[12,45]$. The qLA2-12 on $2 \mathrm{HL}$ is different from the QTL reported on
2HS [12]. In our study, one region on chromosome $2 \mathrm{H}$ flanked by Bmag829 and GBM1218 contained the qPn2-10, qLA2-12, qSPD2-10 and qLNC2-10 (Figure 1), suggesting that there might be QTL cluster for controlling grain yield on chromosome $2 \mathrm{H}$, and these molecular makers can be used for MAS to improve breeding efficiency.

Since year effects and genotype $\times$ year interactions were not significant $(p>0.05)$ for three morphological traits (LA, FLL, FLW), QTL analysis was performed for data from each year and mean value of two years. In our study, 16 QTLs associated with the 3 morphological traits (LA, FLL and FLW) were identified in two years and mean values, which located on chromosome $2 \mathrm{H}$, $3 \mathrm{H}, 4 \mathrm{H}$ and $7 \mathrm{H}$, respectively. Elberse et al. [46] detected 6 QTLs underlying leaf length on chromosome $1 \mathrm{H}, 2 \mathrm{H}$, $4 \mathrm{H}$ and $5 \mathrm{H}, 3$ QTLs controlling leaf width on chromosome $2 \mathrm{H}, 4 \mathrm{H}$ and $6 \mathrm{H}$. Li et al. [45] reported a chromosome region on $3 \mathrm{HS}$ underlying leaf length and leaf area. Gyenis et al. [10] reported 3 QTLs controlling flag leaf length on chromosome $3 \mathrm{H}, 5 \mathrm{H}$ and $7 \mathrm{H}$, and 3 QTLs underlying flag leaf width on $2 \mathrm{H}, 4 \mathrm{H}$ and $5 \mathrm{H}$. Xue et al. [11] detected 2 QTLs controlling flag leaf length on chromosome $5 \mathrm{H}$ and $7 \mathrm{H}$, and 2 QTLs controlling flag leaf width on chromosome $5 \mathrm{H}$. The QTL qFLL2-12 located on chromosome $2 \mathrm{HL}$, and is different from the QTL reported on 2HS [46]. The QTL, qFLW2-12 located on chromosome $2 \mathrm{HL}$, and is different from those QTLs reported on 2HS $[10,46]$. The 3 morphological traits were significantly correlated with each other (Table 3), a common QTL close to the marker GBM1218 on chromosome $2 \mathrm{H}$ controlled these traits (Figure 1; Table 4). Phenotypic correlations among traits and identification of QTL were generally in good agreement. QTLs controlling LA, FLL and FLW were detected on the same region of chromosome $2 \mathrm{H}$ in both years and mean values. This region was close to the marker GBM1218, and contained the qLA2-12, qFLL212 and qFLW2-12 (Figure 1), indicating that this region is important for controlling morphological trait in barley. Moreover, all QTL positive alleles except qLA3-9 and qFLW4-18 were contributed by Huadamai 6 .

Photosynthesis process assimilates $\mathrm{H}_{2} \mathrm{O}$ and $\mathrm{CO}_{2}$ to produce carbohydrates, and can be influenced by plant water status. Relative water content of flag leaf is one important assessment criterion about plant water status [47]. In our study, one common QTL on the chromosome $6 \mathrm{H}$ is close to marker GMS6. Teulat et al. [40] detected one QTL on the chromosome $6 \mathrm{H}$ under two different water treatments. Another study also detected two QTLs on the long arm of chromosome 6H [16]. Previous studies on QTL underlying RWC trait of barley flag leaf found 2 genome regions on the chromosome $6 \mathrm{H}$ associated with RWC, which were close to BCD348B and $B C D 1$, respectively $[13,16,40,41]$. These suggested 
that there might be a QTL cluster in this region. Chromosome $7 \mathrm{H}$ have 3 genome regions associated with RWC, which are nearby RZ123, Acl3 and Bass1B, respectively $[13,16,40,41]$. The QTL qRWC6-6 detected in present study was close to the marker BCD348B, and the QTL qRWC7-9 was close to the marker RZ123.

In our study, two QTL cluster regions associated with physiological and morphological traits, one each on the chromosome $2 \mathrm{H}$ and $7 \mathrm{H}$, were observed (Figure 1). The head type trait was mapped on chromosome $2 \mathrm{H}$ between marker GBM1218 and Bmac93, which is close to the QTL cluster region (Figure 1). The heading date trait was also mapped on chromosome $2 \mathrm{H}$ close to marker GBM1218 in the QTL cluster region [43]. The dwarfing gene was mapped on chromosome $7 \mathrm{H}$ in the QTL cluster region [48]. The head type, heading date and plant height traits were considered to be significantly associated with grain yield $[43,49,50]$. The $v r s 1$ locus controlling head type was mapped on chromosome $2 \mathrm{H}$ [51,52]. From http://wheat.pw.usda.gov/GG2/index.shtml, we found that the marker GBM1218 was close to vrs1 locus. Considering all information here, we suggested that the head type, heading date and plant height traits might be highly associated with these physiological and morphological traits, and could be considered as important factors to control grain yield. Pleiotropy and linkage were present in some important traits associated with yield parameters [53]. In present study, there exist widely co-localized QTL between physiological and morphological traits, such as Pn, Gs, SPD, LNC traits on chromosome $2 \mathrm{H}$ nearby the marker Bmag829, and LA, FLL, FLW traits on chromosome $2 \mathrm{H}$ nearby the marker GBM1218, where the vrs 1 locus was mapped to. There is always a concentration of QTL effects in the vrs1 locus. The co-localization of these QTL is most likely due to pleiotropic effect or gene linkage. Distinguishing linkage from pleiotropy is important for breeding purposes, especially if both desirable and undesirable traits are associated with the same locus or QTL region [13]. Thus, in order to distinguish linkage and pleiotropy, further study is needed.

\section{Conclusions}

In this study, physiological and morphological traits showed significant difference in two parents Huaai 11 and Huadamai 6. We found that chromosome $2 \mathrm{H}$ and $7 \mathrm{H}$ each contained a QTL cluster region controlling grain yield. The molecular makers (Bmag829 and GBM1218) identified here can be used for marker assisted selection to improve breeding efficiency.

\section{Methods}

\section{Plant materials and field experiments}

A barley DH population consisting of $122 \mathrm{DH}$ lines was derived from a cross between dwarfing barley cultivar
Huaai 11 (six-rowed and dwarfing) and common feed barley cultivar Huadamai 6 (two-rowed and tall plant) using anther culture. The two parents Huaai 11 and Huadamai 6 are significant difference in plant height [48], physiological and morphological traits of flag leaf. Experiment was conducted in a rain shelter of the Huazhong Agricultural University, Wuhan, China. Side window of the rain shelter was open to make inside temperature and radiation similar to outside condition. The experiments were performed in year 2012 and 2013. The DH lines and parents were grown in a plot of $1.5 \mathrm{~m}$ long with interval of $0.6 \mathrm{~m}$ and 3 replications using a randomized complete block design. Twenty seeds from each DH line and parent were sown in two rows per plot. Prior to seeding, compound fertilizer $\left(60 \mathrm{~g} / \mathrm{m}^{2}\right)$ was applied, and $20 \mathrm{~g} / \mathrm{m}^{2}$ of urea were applied at the elongation stage. At the prefilling stage, fully expanded flag leaves from main spike were sampled and used to measure 7 physiological and 3 morphological traits.

\section{Quantification of physiological traits of flag leaf at the pre-filling stage}

Four physiological traits, net photosynthetic rate (Pn, umol $\mathrm{CO}_{2} \mathrm{~m}^{-2} \mathrm{~s}^{-1}$ ), stomatal conductance (Gs, mol $\mathrm{H}_{2} \mathrm{O}$ $\left.\mathrm{m}^{-2} \mathrm{~s}^{-1}\right)$, intercellular $\mathrm{CO}_{2}$ concentration $\left(\mathrm{Ci}, \mu \mathrm{mol} \mathrm{CO}_{2}\right.$ $\mathrm{mol}^{-1}$ ) and transpiration rate $\left(\mathrm{Tr}, \mathrm{mmol} \mathrm{H}_{2} \mathrm{O} \mathrm{m}^{-2} \mathrm{~s}^{-1}\right)$, were measured using LI6400 XT Portable photosynthesis system according to the methods described in [54]. Measuring time was selected during 9:00-11:00 am and 2:00-4:00 pm. Three fully expanded and sun-exposed topmost flag leaves on main stem from each replication were measured. The parameters were set as follow: LeafFan at Fast, Flow at $500 \mu \mathrm{mols}^{-1}$, Mixer at $400 \mathrm{ppm}$, Temp at off and Lamp according to the light intensity. The data was recorded after these parameters reading became relatively stable (usually about $1 \mathrm{~min}$ ).

\section{RWC quantification}

Weighing method was applied to measure relative water content (RWC) in flag leaves [16]. A flag leaf was sampled from each replication and measured 3 times. After fresh leaves weighted $(\mathrm{fw})$, leaves were immersed in a sealed bag containing distilled water, and kept for 24 hours to achieve completely rehydration. Then the turgid leaves were weighted (tw), and dried to constant weight $(\mathrm{dw})$. RWC was calculated as: $\mathrm{RWC}=(\mathrm{fw}-\mathrm{dw}) /$ $(\mathrm{tw}-\mathrm{dw}) \times 100 \%$.

\section{SPD quantification}

SPAD-502 chlorophyll photometer was used to measure relative chlorophyll content (SPD) of flag leaves at the prefilling stage. Four flag leaves from each replication were measured. SPD values in the top, medium and bottom part of flag leaf were averaged from three replications. 


\section{LNC quantification}

Leaf nitrogen concentration (LNC) was measured using the Kjeldahl Nitrogen determination method. Ten flag leaves from each replication were collected at the prefilling stage, immediately dried at $105^{\circ} \mathrm{C}$ in an oven for at least $4 \mathrm{~h}$ and then ground into powder using Whirlwind grinding JFS-13A, and stored at $80^{\circ} \mathrm{C}$ until use. Hanon SH220 was used to digest $0.2 \mathrm{~g}$ flag leaf powder. The digestive juice was put in distillation Hanon K9840 Kjeldahl Auto Analyzer to measure consumed volume of standard HCL. Total nitrogen in flag leaf (\%) was calculated using the formula:

$$
L N C(\%)=\frac{C \times(V-V 0) \times 14 \times 100}{M \times 10 \times 1000} \times 100
$$

Where: $C$ is concentration of standard HCL in the titration $(\mathrm{mol} / \mathrm{L}) ; V$ is consumed volume of standard $\mathrm{HCL}$ in the titration sample $(\mathrm{ml}) ; V_{O}$ is consumed volume of standard HCL in the titration blank group (ml); 14 is the atomic mass of nitrogen (g); 100 is total volume of digestive juice $(\mathrm{ml}) ; 10$ is extract volume of digestive juice $(\mathrm{ml}) ; M$ is powder weight of sample $(\mathrm{g})$.

\section{Quantification of morphological traits}

Flag leaf area (LA, area of total leaf, in $\mathrm{cm}^{2}$ ), flag leaf length (FLL, from base of ligula to tip of leaf, in $\mathrm{cm}$ ) and flag leaf width (FLW, widest part of leaf, in $\mathrm{cm}$ ) were measured using LI-3000C Portable Area Meter. Four flag leaves of main spike from each replication were measured.

\section{Data analysis}

Statistics, correlation and QTL analyses were performed for the data from each year. Mean value from two years was also used for QTL analysis if genotype $\times$ year interaction did not reach significant level for that trait. Homogeneity of variance and normality of distribution were tested before analysis of variance (ANOVA). Heritability was calculated for each trait using ANOVA analysis. The General Linear Model was used for analysis of variance. All analyses were performed using IBM SPSS Statistics 19 software. P value less than 0.05 was considered as significance.

Linkage map was constructed using the software MAPMAKER version 3.0 [55]. Genetic distance (centiMorgans, $c M)$ was derived from Kosambi function. The software MapChart 2.2 was used to draw QTL location on the map.

Total of 153 SSR markers evenly distributed on 7 barley chromosomes were used to construct a barley linkage map as previous described $[43,48]$. The most likely location of QTL and their genetic effects were detected by composite interval mapping (CIM) using QTL Cartographer version 2.5 [56]. After performing 1000 permutation test, a LOD threshold of 3.0 was used to declare presence of a putative QTL in a given genomic region [57]. Composite interval mapping (CIM) was employed to identify QTL using Model 6 of the Standard module. Cofactors were chosen using the forward-backward method of stepwise regression. The genome was scanned at $2 \mathrm{cM}$ intervals and the window size set at $10 \mathrm{cM}$. Percentage of phenotypic variation explained and additive effect of each QTL were also calculated by QTL Cartographer 2.5. QTL name was composed of q, the abbreviation of trait, the location of chromosome and the marker position on chromosome.

\section{Abbreviations \\ DH: Double haploid; QTL: Quantitative trait locus; MAS: Marker assisted selection; Pn: Net photosynthetic rate; Gs: Stomatal conductance; $\mathrm{Ci}$ : Intercellular $\mathrm{CO}_{2}$ concentration; Tr: Transpiration rate; LA: Flag leaf area; FLL: Flag leaf length; FLW: Flag leaf width; RWC: Relative water content; SPD: Relative chlorophyll content; LNC: Leaf nitrogen concentration.}

\section{Competing interests}

The authors declare that they have no competing interests.

\section{Authors' contributions}

$\mathrm{LL}$ performed this study, statistical analysis and manuscript writing. XR assisted in phenotyping and software analysis. DS and GS conceived this study, coordinated the experiments, and wrote the manuscript. CL produced the Huaai 11 and Huadamai $6 \mathrm{DH}$ population. All authors have read and approved the final version of this manuscript.

\section{Acknowledgements}

This project was supported in part by the National Natural Science Foundation of China (31301310 and 31228017) and the earmarked fund for China Agriculture Research System (CARS-5).

\section{Author details}

${ }^{1}$ College of Plant Science and Technology, Huazhong Agricultural University, Wuhan 430070, China. Biology Department, Saint Mary's University, 923 Robie Street, Halifax, NS B3H 3C3, Canada. ${ }^{3}$ Department of Agriculture and Food/Agricultural Research Western Australia, 3 Baron-Hay Court, South Perth, WA 6155, Australia. ${ }^{4}$ Hubei Collaborative Innovation Center for Grain Industry, Wuhan 430070, China.

Received: 10 December 2014 Accepted: 6 March 2015

Published online: 20 March 2015

\section{References}

1. Horsley RD, Franckowiak JD, Schwarz PB. Barley. In: Carena MJ, editor. Cereals. US: Springer; 2009. p. 227-50.

2. Teng S, Qian Q, Zeng D, Kunihiro Y, Fujimoto K, Huang D, et al. QTL analysis of leaf photosynthetic rate and related physiological traits in rice (Oryza sativa L). Euphytica. 2004;135:1-7.

3. Berdahl JD, Rasmusson DC, Moss DN. Effects of leaf area on photosynthetic rate, light penetration, and grain yield in barley. Crop Sci. 1972;12:177-80.

4. Flood PJ, Harbinson J, Aarts MG. Natural genetic variation in plant photosynthesis. Trends Plant Sci. 2011;16:327-35.

5. Sarrafi A, Planchon C, Ecochard R, Sioud Y. Inheritance of some physiological factors of productivity in barley. Genome. 1987;29:846-9.

6. Tungland L, Chapko LB, Wiersma JV, Rasmusson DC. Effect of erect leaf angle on grain yield in barley. Crop Sci. 1987;27:37-40.

7. Yap TC, Harvey BL. Relations between grain yield and photosynthetic parts above the flag leaf node in barley. Can J Plant Sci. 1972;52:241-6.

8. Sicher RC. Assimilate partitioning within leaves of small grain cereals. In: Abrol YP, Mohanty P, Govindjee, editors. Photosynthesis: Photoreactions to Plant Productivity. Netherlands: Springer; 1993. p. 351-60.

9. Thorne GN. Photosynthesis of ears and flag leaves of wheat and barley. Ann Bot. 1965;29:317-29.

10. Gyenis L, Yun SJ, Smith KP, Steffenson BJ, Bossolini E, Sanguineti MC, et al. Genetic architecture of quantitative trait loci associated with morphological and agronomic trait differences in a wild by cultivated barley cross. Genome. 2007:50:714-23. 
11. Xue D, Chen M, Zhou M, Chen S, Mao Y, Zhang G. QTL analysis of flag leaf in barley (Hordeum vulgare L.) for morphological traits and chlorophyll content. J Zhejiang Uni Sci B. 2008;9:938-43.

12. Yin X, Kropff MJ, Stam P. The role of ecophysiological models in QTL analysis: the example of specific leaf area in barley. Heredity. 1999;82:415-21.

13. Diab AA, Teulat-Merah B, This D, Ozturk NZ, Benscher D, Sorrells ME. Identification of drought-inducible genes and differentially expressed sequence tags in barley. Theo Appl Genet. 2004;109:1417-25.

14. Guo P, Baum M, Varshney RK, Graner A, Grando S, Ceccarelli S. QTLs for chlorophyll and chlorophyll fluorescence parameters in barley under postflowering drought. Euphytica. 2008;163:203-14.

15. Mickelson S, See D, Meyer FD, Garner JP, Foster CR, Blake TK, et al. Mapping of QTL associated with nitrogen storage and remobilization in barley (Hordeum vulgare L.) leaves. J Exp Bot. 2003;54:801-12.

16. Teulat B, Zoumarou-Wallis N, Rotter B, Salem MB, Bahri H, This D. QTL for relative water content in field-grown barley and their stability across Mediterranean environments. Theor Appl Genet. 2003;108:181-8.

17. This D, Borries C, Souyris I, Teulat B. QTL study of chlorophyll content as a genetic parameter of drought tolerance in barley. Barley Genet Newsl. 2000;30:20-3.

18. Wójcik-Jagła M, Rapacz M, Tyrka M, Kościelniak J, Crissy K, Żmuda K. Comparative QTL analysis of early short-time drought tolerance in Polish fodder and malting spring barleys. Theor Appl Genet. 2013;126:3021-34.

19. Qi X, Stam P, Lindhout P. Comparison and integration of four barley genetic maps. Genome. 1996;39:379-94.

20. Wenzl P, Li H, Carling J, Zhou M, Raman H, Paul E, et al. A high-density consensus map of barley linking DArT markers to SSR. RFLP and STS loci and agricultural traits. BMC Genomics. 2006;7:206.

21. Horton P. Prospects for crop improvement through the genetic manipulation of photosynthesis: morphological and biochemical aspects of light capture. J Exp Bot. 2000;51:475-85.

22. Rawson HM, Constable GA. Carbon production of sunflower cultivars in field and controlled environments. I. Photosynthesis and transpiration of leaves, stems and heads. Funct Plant Biol. 1980;7:555-73.

23. Jiang $\mathrm{Q}$, Roche $\mathrm{D}$, Monaco TA, Hole $\mathrm{D}$. Stomatal conductance is a key parameter to assess limitations to photosynthesis and growth potential in barley genotypes. Plant Biol. 2006;8:515-21.

24. Rybiński W, Garczyński S. Influence of laser light on leaf area and parameters of photosynthetic activity in DH lines of spring barley (Hordeum vulgare L.). Int Agrophys. 2004;18:261-8.

25. Rhodes MJC, Yemm EW. The development of chloroplasts and photosynthetic activities in young barley leaves. New Phytol. 1966;65:331-42.

26. Von Korff M, Grando S, Del Greco A, This D, Baum M, Ceccarelli S. Quantitative trait loci associated with adaptation to Mediterranean dryland conditions in barley. Theor Appl Genet. 2008;117:653-69.

27. Araus JL, Amaro T, Voltas J, Nakkoul H, Nachit MM. Chlorophyll fluorescence as a selection criterion for grain yield in durum wheat under Mediterranean conditions. Field Crops Res. 1998;55:209-23.

28. Siahsar BA, Aminfar Z. Mapping QTLs of physiological traits associated with salt tolerance in 'Steptoe' $\times$ 'Morex' doubled haploid lines of barley at seedling stage. J Food Agric Environ. 2010;8:751-9.

29. Yang L, Mickelson S, See D, Blake TK, Fischer AM. Genetic analysis of the function of major leaf proteases in barley (Hordeum vulgare L.) nitrogen remobilization. J Exp Bot. 2004;55:2607-16.

30. Sinclair TR, Horie T. Leaf nitrogen, photosynthesis, and crop radiation use efficiency: a review. Crop Sci. 1989;29:90-8.

31. Lewis OAM, James DM, Hewitt EJ. Nitrogen assimilation in barley (Hordeum vulgare L. Cv. Mazurka) in response to nitrate and ammonium nutrition. Ann Bot. 1982;49:39-49.

32. Shangguan Z, Shao M, Dyckmans J. Effects of nitrogen nutrition and water deficit on net photosynthetic rate and chlorophyll fluorescence in winter wheat. J Plant Physiol. 2000;156:46-51.

33. Sage RF, Pearcy RW. The nitrogen use efficiency of C3 and C4 plants II. Leaf nitrogen effects on the gas exchange characteristics of Chenopodium album (L.) and Amaranthus retroflexus (L.). Plant Physiol. 1987;84:959-63.

34. Teulat B, Monneveux P, Wery J, Borries C, Souyris I, Charrier A, et al. Relationships between relative water content and growth parameters under water stress in barley: a QTL study. New Phytol. 1997;137:99-107.

35. Johnson RR, Frey NM, Moss DN. Effect of water stress on photosynthesis and transpiration of flag leaves and spikes of barley and wheat. Crop Sci. 1974;14:728-31.
36. González A, Martín I, Ayerbe L. Yield and osmotic adjustment capacity of barley under terminal water-stress conditions. J Agron Crop Sci. 2008;194:81-91.

37. Zhao J, Sun H, Dai H, Zhang G, Wu F. Difference in response to drought stress among Tibet wild barley genotypes. Euphytica. 2010;172:395-403.

38. Matin MA, Brown JH, Ferguson H. Leaf water potential, relative water content, and diffusive resistance as screening techniques for drought resistance in barley. Agron J. 1989:81:100-5.

39. Sinclair TR, Ludlow MM. Who taught plants thermodynamics? The unfulfilled potential of plant water potential. Aust J Plant Physiol. 1985;12:213-7.

40. Teulat B, This D, Khairallah M, Borries C, Ragot C, Sourdille P, et al. Several QTLs involved in osmotic-adjustment trait variation in barley (Hordeum vulgare L.). Theor Appl Genet. 1998;96:688-98.

41. Teulat B, Borries C, This D. New QTLs identified for plant water status, watersoluble carbohydrate and osmotic adjustment in a barley population grown in a growth-chamber under two water regimes. Theor Appl Genet. 2001;103:161-70.

42. Varshney RK, Marcel TC, Ramsay L, Russell J, Röder MS, Stein N, et al. A high density barley microsatellite consensus map with 775 SSR loci. Theor Appl Genet. 2007;114:1091-103.

43. Ren X, Sun D, Sun G, Li C, Dong W. Molecular detection of QTL for agronomic and quality traits in a doubled haploid barley population. Aust J Crop Sci. 2013;7:878-86.

44. Murchie EH, Pinto M, Horton P. Agriculture and the new challenges for photosynthesis research. New Phytol. 2009;181:532-52

45. Li JZ, Huang XQ, Heinrichs F, Ganal MW, Röder MS. Analysis of QTLs for yield components, agronomic traits, and disease resistance in an advanced backcross population of spring barley. Genome. 2006;49:454-66.

46. Elberse IAM, Vanhala TK, Turin JHB, Stam P, van Damme JMM, van Tienderen PH. Quantitative trait loci affecting growth-related traits in wild barley (Hordeum spontaneum) grown under different levels of nutrient supply. Heredity. 2004;93:22-33.

47. Forster BP, Ellis RP, Moir J, Talame V, Sanguineti MC, Tuberosa R, et al. Genotype and phenotype associations with drought tolerance in barley tested in North Africa. Ann Appl Biol. 2004;144:157-68.

48. Ren X, Sun D, Guan W, Sun G, Li C. Inheritance and identification of molecular markers associated with a novel dwarfing gene in barley. BMC Genet. 2010;11:89.

49. Cuesta-Marcos A, Casas AM, Hayes PM, Gracia MP, Lasa JM, Ciudad F, et al. Yield QTL affected by heading date in Mediterranean grown barley. Plant Breed. 2009;128:46-53.

50. García del Moral LF, García del Moral MB, Molina-Cano JL, Slafer GA. Yield stability and development in two-and six-rowed winter barleys under Mediterranean conditions. Field Crops Res. 2003;81:109-19.

51. Pourkheirandish M, Wicker T, Stein N, Fujimura T, Komatsuda T. Analysis of the barley chromosome 2 region containing the six-rowed spike gene vrs 1 reveals a breakdown of rice-barley micro collinearity by a transposition. Theor Appl Genet. 2007;114:1357-65.

52. Komatsuda T, Li W, Takaiwa F, Oka S. High resolution map around the vrs locus controlling two- and six-rowed spike in barley, Hordeum vulgare. Genome. 1999;42:248-53.

53. Marquez-Cedillo LA, Hayes PM, Kleinhofs A, Legge WG, Rossnagel BG, Sato K, et al. QTL analysis of agronomic traits in barley based on the doubled haploid progeny of two elite North American varieties representing different germplasm groups. Theor Appl Genet. 2001;103:625-37.

54. Rapacz M, Kościelniak J, Jurczyk B, Adamska A, Wójcik M. Different patterns of physiological and molecular response to drought in seedlings of maltand feed-type barleys (Hordeum vulgare). J Agron Crop Sci. 2010;196:9-19.

55. Lander ES, Green P, Abrahamson J, Barlow A, Daly MJ, Lincoln SE, et al. MAPMAKER: an interactive computer package for constructing primary genetic linkage maps of experimental and natural populations. Genomics. 1987;1:174-81.

56. Wang S, Basten CJ, Zeng ZB. Windows QTL Cartographer 2.5. Raleigh, NC: Department of Statistics, North Carolina State Univ; 2007.

57. Churchill GA, Doerge RW. Empirical threshold values for quantitative trait mapping. Genetics. 1994;138:963-71. 